\title{
Wettability and color change of thermally treated poplar OSB after accelerated weathering test
}

\author{
Francesco Negro ${ }^{1}$, Paola Cetera ${ }^{2, *}$, Corrado Cremonini ${ }^{1}$, Luigi Todaro ${ }^{2}$ and Roberto Zanuttini ${ }^{1,3}$ \\ 1 DISAFA, University of Torino, Largo Paolo Braccini 2, 10095 Grugliasco, Italy; francesco.negro@unito.it; \\ corrado.cremonini@unito.it; roberto.zanuttini@unito.it \\ 2 School of Agricultural, Forestry, Food and Environmental Science, University of Basilicata. V.le \\ dell'Ateneo Lucano 10, 85100 Potenza, Italy; paola.cetera@unibas.it; luigi.todaro@unibas.it \\ 3 CNR-IVALSA (associate) \\ * Correspondence: paola.cetera@unibas.it; Tel.: +39-3298143179
}

西

\begin{abstract}
Oriented strand board (OSB) panels are widely marketed for several applications, from building to packaging. The manufacturing of poplar OSB started recently in Northern Italy representing a relevant innovation in the sector since this product is usually made of coniferous wood. The thermal treatment is widely used for reducing the hygroscopicity of wood-based products, nonetheless it influences the mechanical behavior and degrades the main components of wood, which can affect their finishing. Therefore, it is important to know the properties of the treated surfaces. To this purpose, in this study a lot of OSB panels, made of poplar wood, $15 \mathrm{~mm}$ thick and with a density of $590 \mathrm{~kg} / \mathrm{m}^{3}$, were thermally treated under vacuum conditions at $190{ }^{\circ} \mathrm{C}$ for $2 \mathrm{~h}$ and then subjected to accelerated weathering. The changes in color and in wettability due to treatment and accelerated weathering were studied. The thermal treatment determined a significant darkening of the color; the accelerated weathering darkened the untreated surfaces and, on the opposite, lightened the thermo-treated surfaces. The wettability decreased after thermal treatment and increased after weathering, more evidently in treated panels. Overall, this study improves the knowledge about the behavior of the surface of thermo-treated poplar OSB, which is relevant for the industrial coating of this product.
\end{abstract}

Keywords: accelerated weathering test; color change; poplar OSB; wettability

\section{Introduction}

Poplar (Populus spp.) is a fast-growing tree with low economic costs in terms of logging and production. The manufacturing of poplar Oriented Strand Board (OSB) started in 2012 in Northern Italy, representing a relevant novelty for the national and European wood sector: OSB, in fact, is typically made entirely or largely of coniferous wood [1]. Production of Poplar OSB has steadily increased from 2014, reaching about the $2 \%$ of the overall OSB volume manufactured in Europe [2]. In perspective this product it is also expected to contribute in sustaining the poplar cultivation sector in Italy, which in the past decades suffered a sensible reduction in plantations coverage [3,4].

The manufacturing process of poplar and coniferous OSB is similar, the main phases being wood stranding, glue spreading and panels pressing. Paraffin is commonly used to detach the panels from the plates of the continuous press adopted for manufacturing and to limit the swelling of the finished panels. Anyway, differences exist in the physical and mechanical characteristics depending on the wood used. Specifically, the density of poplar OSB varies from $500 \mathrm{~kg} / \mathrm{m}^{3}$ to 620 $\mathrm{kg} / \mathrm{m}^{3}$, depending on its thickness; this is about $15 \%$ lower than the density of coniferous OSB, which typically ranges from 600 to $680 \mathrm{~kg} / \mathrm{m}^{3}[5]$. Further, poplar wood also determines a lighter and whitish color of the panel compared to that of coniferous OSB, which generally presents a yellow tone. 
According to product standard EN 300 [6], poplar OSB is currently available in OSB-3 type that is for load-bearing use in humid conditions. In general, OSB is intended for final applications in building and packaging, but some end-uses in furnishing are also relevant [7]. Poplar OSB presents several interesting features making it suitable for various uses in the above sectors, nonetheless the low natural durability of poplar wood (Class 'DC 5 - not durable', according to EN 350 [8]) is a limiting factor in case of exposition in conditions that determine the risk of fungal decay.

Several methods for improving the natural durability of wood exists [9]. Among these, thermal treatment consists in exposing wood to high temperatures, generally from $160{ }^{\circ} \mathrm{C}$ to $230{ }^{\circ} \mathrm{C}$, in a controlled environment. This causes a chemical degradation by heat transfer that modifies several properties of wood. In particular, natural durability and dimensional stability increase, whereas density and mechanical properties decrease; further, the color shifts towards darker tones [10]. Over the past years several processes, mainly differing in inert atmosphere and curing conditions (gases, oil, steam etc.) have been developed; in this context, the thermo-vacuum treatment is performed in vacuum-conditions and is nowadays well-established on the market [11]; recently its potential for extracting chemicals from poplar wood has also been studied [12].

Overall, modified wood is adequate for non-structural uses in humid or exterior environments, for instance in furnishing, flooring and facades [13]. Thermal treatment is therefore often proposed as a means for valorizing wood of species with low natural durability or for finding new applications to timber and related materials having few market outlets [14,15].

Wetting properties are frequently investigated, usually measuring the contact angle (CA), for assessing several aspects regarding processing and performance of wood and derived products [16]. Being wood a porous and hygroscopic material, in fact, its interactions with liquids play a key role in many final applications. These include adhesion, coating, waterproofing, surface modifications, weathering, degradation and liquid absorption $[17,18]$. For instance, the contact angle is generally considered a fundamental parameter determining penetration of adhesives inside wood [19]; spreading and adhesion of coatings on wood strongly depend on CA [20]; changes in the wetting properties have been taken as a major indicator for wood weathering tests [21]. In this context, exposing wood to ultraviolet (UV) light is an effective pretreatment for activation that enables to increase its wettability and it is therefore widely used in the wood coating sector [22,23].

Some relatively recent research has been performed on the thermal treatment of OSB panels. Mendes et al. [24] showed that the physical properties of OSB made with Pinus taeda wood increased after thermal treatment, while the mechanical properties decreased. Anyway, to this day no detailed studies have been reported about the surface degradation of poplar OSB considering the combined effect of thermal treatment and accelerated weathering test (AWT).

To this purpose, in this study the contact angle was recorded on untreated and thermo-treated poplar OSB, exposed and non-exposed to accelerated weathering test. Color change was also determined as an indicator of the intensity of the performed process.

\section{Materials and Methods}

\subsection{Thermal treatment}

Ten poplar OSB panels of nominal thickness $15 \mathrm{~mm}$ were drawn from the standard manufacturing process of the producer. Panels were subjected to thermal treatment under vacuum conditions using the Termovuoto ${ }^{\circledR}$ process. Treatment temperature of $190{ }^{\circ} \mathrm{C}$ was maintained for $2 \mathrm{~h}$. At the end of the process, 30 specimens with dimension of 50x50x15 mm, equally distributed between untreated and thermally-treated panels were randomly cut for sampling and further testing.

\subsection{Color measurement}

Surface color of poplar OSB before and after accelerated weathering test, including the corresponding references, was determined on middle spot of each specimens; five replicas have 
been performed. Color parameters were speedily measured by CR-400 CHROMA METER, which was connected at the Color Data Software SpectraMagic NX for the expression of the results. The color parameters $\left(\mathrm{L}^{*}, \mathrm{a}^{*}, \mathrm{~b}^{*}\right.$, and $\left.\Delta \mathrm{E}^{*}\right)$ were determined by the CIE-L*a* $\mathrm{b}^{*}$ color space system according to ISO 11664-4 [25] (10 standard observer, D65 standard illuminate). The color variations after thermal treatment or UV-exposure were evaluated by overall color change which was calculated according to ISO 11664-4 and ISO 11664-6 [26]:

\subsection{Contact angle}

where: $\quad \Delta \mathrm{E}^{*}$ is the overall color change, $\Delta \mathrm{L}^{*}, \Delta \mathrm{a}^{*}$ and $\Delta \mathrm{b}^{*}$ are the differences between the initial and the final values (between thermo-treated and non-treated panels, before and after accelerated weathering test).

For the analysis of the wettability, contact angle measurements of distilled water on the OSB surface were performed through the sessile drop method by Drop Shape Analyzer System, Krüss software module (Hamburg, Germany). Sessile drops of $2 \mu l$ have been deposited on each specimen for 5 repetitions. 15 replicas for both treated and untreated OSB panels have been done for a total of 150 drops. The contact angle was evaluated for a total duration of $120 \mathrm{~s}$ for each drop, while the right and left angle of the drops on the wood surface were collected at intervals of $0.5 \mathrm{~s}$.

\subsection{Accelerated weathering exposure}

AWT of poplar OSB surface was performed by a QUV Accelerated Weathering Tester. The aim was to reproduce the damage caused by sunlight, rain and dew. The exposure of the wood surfaces of the samples lasted for 168 hours. The cycle consisted of a condensation period followed by a sub-cycle of water spray and UV-A 340 irradiation according to EN 927-6 [27].

\subsection{Statistical analysis}

Effects of thermal treatment and AWT on color and contact angle (after $120 \mathrm{sec}$ ) of poplar OSB were investigated through two-way ANOVA using the software IBM SPSS ver. 24.

\section{Results and Discussion}

\subsection{Color change}

Table 1 shows the average color coordinates measured for untreated (NT) and treated (T), non subjected to wethering test (Pre AWT) and after wethering test (Post AWT) specimens groups, whilst color changes $\left(\Delta \mathrm{E}^{*}\right)$ are shown in Table 2 . 
Table 1. CIELab* coordinates measured for tested specimens.

\begin{tabular}{|l|c|c|c|}
\hline & \multicolumn{3}{|c|}{ CIELab* coordinates } \\
\hline \multicolumn{1}{|c|}{ group code } & $\mathbf{L}^{*}$ & $\mathbf{a}^{*}$ & $\mathbf{b}^{*}$ \\
\hline NT Pre AWT & 77.52 & 4.45 & 21.61 \\
\hline T Pre AWT & 52.16 & 10.28 & 21.38 \\
\hline NT Post AWT & 68.55 & 6.82 & 18.78 \\
\hline T Post AWT & 60.66 & 5.02 & 11.42 \\
\hline
\end{tabular}

133
Table 2. $\Delta \mathrm{E}^{*}$ measured among group code

\begin{tabular}{|l|c|c|c|}
\hline \multicolumn{1}{|c|}{ group code } & NT & T & NT Post AWT \\
\hline NT Pre AWT & - & - & - \\
\hline T Pre AWT & 26.07 & - & - \\
\hline NT Post AWT & 9.90 & 16.95 & - \\
\hline T Post AWT & 11.11 & 14.14 & 10.94 \\
\hline
\end{tabular}

Thermal treatment determined a significant darkening $(p<0.01)$ of the surfaces $\left(\Delta \mathrm{L}^{*}=-25.35\right)$; color also shifted towards red $\left(\Delta \mathrm{a}^{*}=5.83\right)$, whereas changes on the blue-yellow axis were limited $\left(\Delta \mathrm{b}^{*}=-0.23\right)$; overall, the color change $\left(\Delta \mathrm{E}^{*}=26.07\right)$ resulted mainly related to $\Delta \mathrm{L}^{*}$. The darkening of wood color is a typical consequence of thermal treatment, which determines the formation of degradation products from hemicelluloses, the build-up of oxidation products and the modification of extractives [10]. Further, it has been recognized that color and treatment temperature are closely related $[28,29]$.

Accelerated weathering determined a significant $(p<0.01)$ darkening of untreated specimens $\left(\Delta \mathrm{L}^{*}=-8.97\right)$; changes in $\mathrm{a}^{*}$ and $\mathrm{b}^{*}$ coordinates turned out limited $\left(\Delta \mathrm{a}^{*}=2.37, \Delta \mathrm{b}^{*}=-2.83\right)$, therefore the color change $\left(\Delta E^{*}=9.90\right)$ still resulted mainly due to $\Delta \mathrm{L}^{*}$. On the opposite, the color of thermally modified specimens was significantly lighter $(p<0.01)$ after AWT $\left(\Delta \mathrm{L}^{*}=8.42\right)$; in this case the changes in $\mathrm{a}^{*}$ and $\mathrm{b}^{*}$ resulted higher $\left(\Delta \mathrm{a}^{*}=-5.26, \Delta \mathrm{b}^{*}=-9.96\right)$, for a more relevant contribution in color change $\left(\Delta \mathrm{E}^{*}=14.14\right)$. Similar trends have already been reported [30] and show how UV irradiation omogenizes the color of wood. In particular, the lightnening of thermo-treated wood is similar to that occurring in dark colored woods exposed to UV for long time. Overall, the color change of untreated and treated specimens can be mainly attributed to the degradation of lignin, which is extremely susceptible to UV irradiation [30,31].

\subsection{Contact angle}

Figure 1 and 2 show the average values of contact angle, determined using water as liquid test, for untreated and treated specimens, pre- and post-weathering. 
untreated OSB

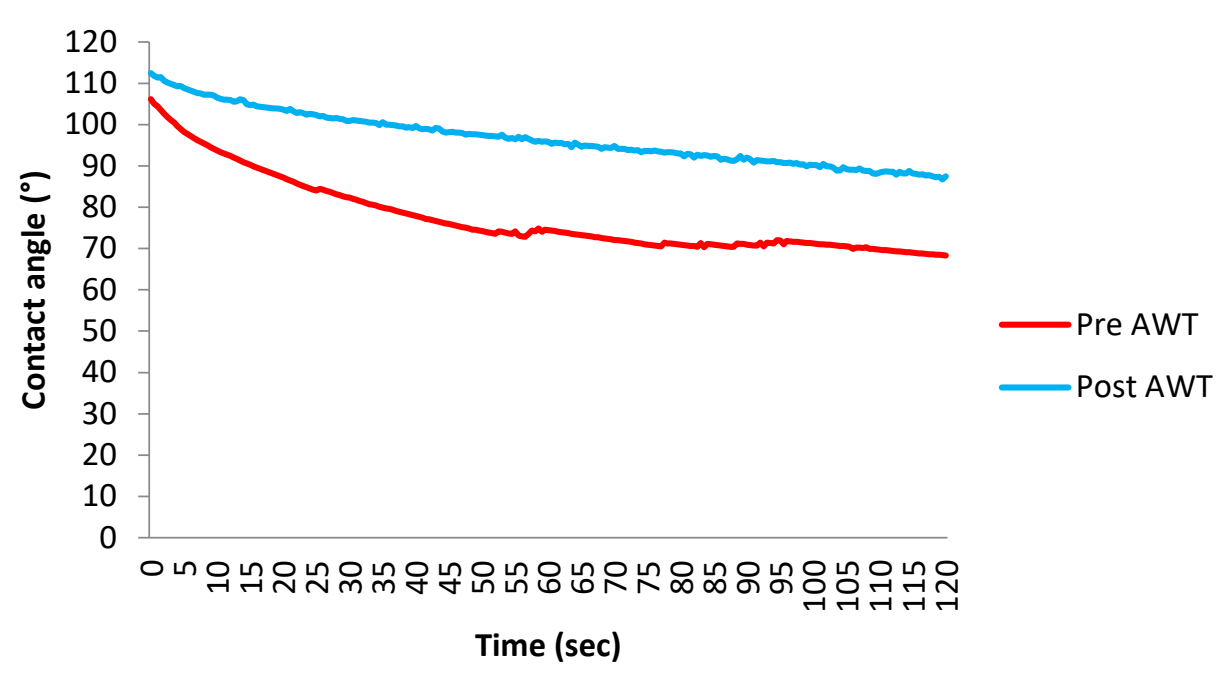

156

Figure 1. Contact angle variation in untreated OSB panels before and after weathering.

Figure 2.Contact angle variation in treated OSB panels before and after weathering.

treated OSB

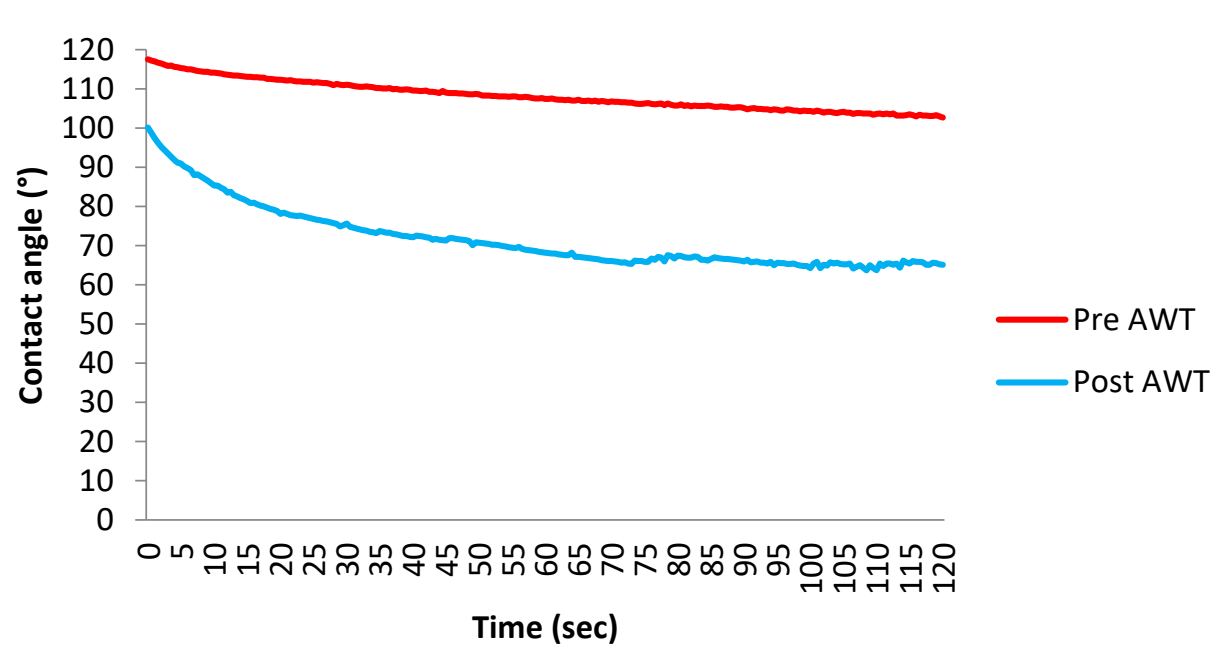

The thermal treatment determined a significant $(p<0.01)$ decreasing in wettability. In fact, after $120 \mathrm{sec}$ the pre-AWT CA of thermo-treated OSB $\left(120.7^{\circ}\right)$ resulted almost twice the pre-AWT CA of untreated OSB $\left(68.3^{\circ}\right)$. The lower wettability of the panels surface after thermal treatment can be mainly ascribed to the phenomena of degradation occurring during the process, which modifies some chemical features of wood. In particular, the main reason are the migration of non-polar extractives to the surface during heating [32] and the cross-linking between the lignin and polysaccharides, with a consequent reduction in free hydroxyl groups among the hemicelluloses that changes during heating and may undergo oxidation reactions [33].

For untreated OSB, after $120 \mathrm{sec}$ the pre-AWT CA $\left(68.3^{\circ}\right)$ resulted significantly lower $(p<0.01)$ than the post-AWT CA $\left(87.5^{\circ}\right)$. On the contrary, for treated OSB after $120 \mathrm{sec}$ the pre-AWT CA $\left(120.7^{\circ}\right)$ is significantly higher $(p<0.01)$ than the post-AWT CA $\left(65.1^{\circ}\right)$, highlighting a loss of the effect 
previously gained through thermal treatment. It can also be noted that, after weathering, the CA line of untreated OSB shows a constant trend in time (Fig. 1), which could further decrease, whereas that of thermo-treated OSB becomes rather stable after about $70 \mathrm{sec}$ (Fig. 2). Overall, the exposure to UV irradiation can represent a method for reactivating the surface of thermo-treated poplar OSB in view of industrial coatings and finishing processes.

\section{Conclusions}

The aim of the present work was to evaluate the wettability and the color change of poplar OSB, taking into account the effects of heating and accelerated weathering test. The results obtained give some evidence in terms of color and wettability change. In this regard, the hydrophobicity of poplar OSB increased after thermal treatment, whereas the surface degradation due to weathering test caused a decreasing slightly stronger in thermally treated panels, at least after $120 \mathrm{sec}$. The results are interesting for several industrial applications in which it is essential to take into account any change in wetting properties. In particular, the weathering enabled to increase the wettability of thermally treated OSB and this effect can be further evaluated or exploited for improving the coating of this panel and similarly treated wood materials whose use is recently recording a wide market diffusion.

Acknowledgments: The experimental activity related to thermal treatment was realized within the PRIN2015 project (n. 20015YW8JWA) "Short chain in the biomass-wood sector: supply, traceability, certification and carbon sequestration. Innovations for bio-building and energy efficiency". The Ph.D. program in Agricultural, Forest and Food Sciences, at the University of Basilicata, supported P. Cetera. The scholarship of the Erasmus+ Program, supported Paola Cetera at the Institut für Holztechnologie und Nachwachsende Rohstoffe in Tulln (Austria) coordinated by W. Gindl-Altmutter.

Author Contributions: F. Negro wrote a main part of the paper and performed the statistical analysis; P. Cetera, corresponding author, wrote a main part of the paper and performed the experimental testing; Corrado Cremonini, Luigi Todaro and Roberto Zanuttini conceived and designed the study, and revised the paper contributing to its drafting; all authors participated to the discussion of the work.

Conflicts of Interest: The authors declare no conflict of interest. The founding sponsors had no role in the design of the study; in the collection, analyses, or interpretation of data; in the writing of the manuscript, and in the decision to publish the results.

\section{References}

1. Theomen, H.; Irle, M.; Sernek, M.Wood-based panels. An introduction for specialists, (ed.); Brunel University Press, London, England, 2008; 283 pp., ISBN 978-1-902316-82-6.

2. EPF. Annual report 2016-2017; European Panel Federation, Brussels, Belgium, 2017; 276 pp.

3. Levarato, G.; Pra, A.; Pettenella, D. Which future for poplar cultivation. Survey on the current framework and on the perspectives of industrial use of poplar wood (in Italian). Etifor srl - Spin-off dell'Università di Padova: Padova, Italy, 2008; 77 pp., ISBN 978-88-943378-0-8.

4. Castro, G.; Zanuttini, R. Poplar cultivation in Italy: history, state of the art, perspectives. In Proceedings of the COST Action E44 Final Conference on a European wood processing strategy: future resources matching products and innovations, Milan, Italy, 30 May 2008; pp. 141-154.

5. EPF. Technical Information Sheet. OSB (Oriented Strand Board). Available online: www.osb-info.org (accessed on 08 March 2018).

6. EN 300 Oriented Strand Boards (OSB). Definitions, classification and specifications; CEN: Brussels, Belgium, 2006.

7. Tabarsi, E.; Kozak, R.; Cohen, D.; Gaston, C. A market assessment of the potential for OSB products in the North American office furniture and door manufacturing industries. For. Prod. J. 2003, 53(7/8), 19-27.

8. EN 350 Durability of wood and wood-based products - Testing and classification of the durability to biological agents of wood and wood-based materials; CEN: Brussels, Belgium, 2016. 
9. Hill, C.A.S. Wood modification: chemical, thermal and other processes. John Wiley \& Sons: Chichester, England, 2006; 260 pp., ISBN 978-0-470-02172-9.

10. Candelier, K.; Thevenon, M.F.; Petrissans, A.; Dumarcay, S.; Gerardin, P.; Petrissans, M. Control of wood thermal treatment and its effects on decay resistance: a review. Ann. For. Sci. 2016, 73, 571-583. doi: 10.1007/s13595-016-0541-x.

11. Cuccui, I.; Negro, F.; Zanuttini, R.; Espinoza, M.; Allegretti, O. Thermo-vacuum modification of Teak wood from fast-grown plantations. BioResources 2017, 12(1), 1903-1915. doi: 10.15376/biores.12.1.1903-1915.

12. Todaro, L.; Russo, D.; Cetera, P.; Milella, L. Effects of thermo-vacuum treatment on secondary metabolite content and antioxidant activity of Poplar (Populus nigra L.) wood extracts. Ind. Crop. Prod. 2017, 109, 384-390. doi: 10.1016/j.indcrop.2017.08.052.

13. Todaro L. Effect of steaming treatment on resistance to footprints in Turkey oak wood for flooring. Eur. J. Wood Wood Prod. 2012, 70(1), 209-214. doi: 10.1007/s00107-011-0542-2.

14. Sandak, A.; Allegretti, O.; Cuccui, I.; Sandak, J.; Rosso, L.; Castro, G.; Negro, F.; Cremonini, C.; Zanuttini, R. Thermo-vacuum modification of Poplar veneers and its quality control. BioResources 2016, 11(4), 10122-10139. doi: 10.15376/biores.11.4.10122-10139.

15. Todaro, L.; Rita, A.; Negro, F.; Moretti, N.; Saracino, A.; Zanuttini, R. Behavior of pubescent oak (Quercus pubescensWilld.) wood to different thermal treatments. iForest 2015, 8, 748-755. doi: 10.3832/ifor1348-007.

16. Pánek, M.; Oberhofnerová, E.; Zeidler, A.; Šedivka, P. Efficacy of hydrophobic coatings in protecting oak wood surfaces during accelerated weathering. Coatings 2017, 7(10): 172. doi: 10.3390/coatings7100172.

17. Petrič, M.; Oven, P. Determination of wettability of wood and its significance in wood science and technology: a critical review. Rev. Adhes. Adhes. 2015, 3, 121-187. doi: 10.7569/RAA.2015.097304.

18. Bryne, L.E.; Wålinder, M.E.P. Ageing of modified wood. Part 1: Wetting properties of acetylated, furfurylated, and thermally modified wood. Holzforschung 2010, 64, 295-304. doi: 10.1515/hf.2010.040.

19. Cheng, E.; Sun, X. Effects of wood-surface roughness, adhesive viscosity and processing pressure on adhesion strength of protein adhesive. J. Adhes. Sci. Technol. 2006, 20(9), 997-1017. doi: 10.1163/156856106777657779.

20. Kúdela, J.; Liptáková, E. Adhesion of coating materials to wood. J. Adhes. Sci. Technol. 2006, 20(8), 875-895.doi: 10.1163/156856106777638725.

21. De Vetter, L.; Van den Bulcke, J.; Van Acker, J. Impact of organosilicon treatments on the wood-water relationship of solid wood. Holzforschung 2010, 64, 463-468.doi: 10.1515/hf.2010.069.

22. Landry, V.; Blanchet, P.; Boivin, G.; Bouffard, J.F.; Vlad, M. UV-LED curing efficiency of wood coatings. Coatings 2015, 5(4), 1019-1033. doi: 10.3390/coatings5041019.

23. Gindl, M.; Sinn, G.; Stanzl-Tschegg, S.E. The effects of ultraviolet light exposure on the wetting properties of wood.J. Adhes. Sci. Technol. 2006, 20(8), 817-828. doi:10.1163/156856106777638653.

24. Mendes, R. F.; Júnior, G. B.; de Almeida, N. F.; Surdi, P. G.; Barbeiro, I. N. Effect of thermal treatment on properties of OSB panels. Wood Sci. Technol. 2013, 47(2), 243-256. doi: 10.1007/s00226-012-0494-7.

25. ISO 11664-4 Colorimetry -- Part 4: CIE $1976 L^{*} a^{*} b^{*}$ Colour space. ISO: Geneva, Switzerland, 2008.

26. ISO 11664-6 Colorimetry -- Part 6: CIEDE2000 Colour-difference formula.ISO: Geneva, Switzerland, 2013.

27. EN 927-6 Paints and varnishes - Coating materials and coating systems for exterior wood - Part 6: Exposure of wood coatings to artificial weathering using fluorescent UV lamps and water. CEN: Brussels, Belgium, 2006.

28. Kačíková, D.; Kačík, F.; Čabalová, I.; Ďurkovič, J. Effects of thermal treatment on chemical, mechanical and color traits in Norway spruce wood. Bioresour. Technol. 2013, 144, 669-674. doi: 10.1016/j.biortech.2013.06.110.

29. Welzbacher, C.R.; Brischke, C.; Rapp, O.A. Influence of treatment temperature and duration on selected biological, mechanical, physical and optical properties of thermally modified timber. Wood Mat. Sci. Eng. 2007, 2, 66-76. doi: 10.1080/17480270701770606.

30. Srinivas, K.; Pandey, K.K. Photodegradation of thermally modified wood. J. Photochem. Photobiol. B-Biol. 2012, 117, 140-145. doi: 10.1016/j.jphotobiol.2012.09.013.

31. Teacă, C.A.; Roşu, D.; Bodîrlău, R.; Roşu, L. Structural changes in wood under artificial UV light irradiation determined by FTIR spectroscopy and color measurements - a brief review. BioResources 2013, 8(1), 1478-1507. doi: 10.15376/biores.8.1.1478-1507.

32. Tjeerdsma, B.F.; Militz, H. Chemical changes in hydrothermal treated wood: FTIR analysis of combined hydrothermal and dry heat-treated wood. Eur. J. Wood Wood Prod. 2005, 63(2), 102-111. doi: 10.1007/s00107-004-0532-8. 
275 33. Esteves, B.; Marques, A.V.; Domingos, I.; Pereira, H. Influence of steam heating on the properties of pine (Pinus pinaster) and eucalypt (Eucalyptus globulus) wood. Wood Sci. Technol. 2007, 41(3), 193. doi:10.1007/s00226-006-0099-0. 